of special importance for specific problems (for example, cancer) ; (5) to devise measures for ensuring adequate supplies of needed animal stocks in states of emergency (war, epidemics, etc.); and (6) to assist in the organization and facilitation of the international exchange of needed animal stocks.

The first publication of the Institute is a "Handbook of Laboratory Animals"*. This handbook has a page on genetics, by Dr. George E. Jay, jun. ; a page and a half on nutrition, by Dr. Charles $\mathbf{A}$. Slinetz; a page on diseases of laboratory animals, by Dr. N. R. Brewer, followed by twelve pages summarizing the more common infections of a wide variety of species; an extensive table of sources of animal supply ; three pages on the uses of laboratory animals, with an extensive bibliography of uses; a short selection of general references; a table of users of laboratory animals; and a brief note on the importance and desirability of international exchange, both of information and of strains of animals of particular interest, which we in Great Britain can whole-heartedly endorse.

The main part of the handbook is occupied by the two tables, which have been compiled from the answers to questionnaires sent out by the Institute. The table of sources of animal supply is subdivided by species, and covers mice, rats, guinea pigs, rabbits, hamsters, dogs, monkeys, chicks and a wide variety of miscellaneous animals. There are columns showing strain, original source, breeding system, description, diet, disease control measures, uses and productive output, against each source of supply, which includes both laboratories and commercial breeders and suppliers. Although this list is far from complete for the country as a whole, and probably represents only a minority of total sources, it is formidable, and will undoubtedly be an immensely useful catalogue for any scientific worker wishing to select the most suitable animals for his researches. The tabulation is : clear, and most of the information essentially useful. (A counterpart of this table is the "Laboratory Animals Bureau Catalogue of Uniform Strains maintained in Great Britain".) Further additions to the table have been promised, and any approach towards comprehensiveness will certainly enhance its value.

The list of uses of laboratory animals is certainly very incomplete, but, taken in conjunction with the table of sources, is a worth-while guide. Its expansion in subsequent issues would make it a useful reference index.

The second table, listing users of laboratory animals, contains information essential to the functioning of the Institute, but it is harder to see what interest it can have for others. Had it been necessary to show that the Institute was in fact well occupied, its inclusion in the handbook might have been justified, but the rest of the handbook is already sufficient evidence.

Such criticism of the Institute's work may appear ungenerous, but this would be a false impression. The Institute has undertaken a task, both of urgent necessity and of a complexity incomparably greater than in Great Britain, where the numbers of laboratories, of scientific workers and of animals used are so much smaller. It has tackled the problem with the vigour to be expected of our American colleagues, and the handbook, produced within two years of the

- Handbook of Laboratory Animals. (Pub. No. 317 of the National Academy of Sciences-National Research Council.) Prepared by the Institute of Animal Resources. Pp. v +77. (Washington, D.C., 1954.) 1.25 dollars. establishment of the Institute, is ample tribute to its competence and industry. Only one who has faced similar tasks elsewhere can appreciate how much thought and work went into this enterprise, and we look forward with ergerness and confidence to further publications from the same source.

\section{PROFESSIONAL STATUS OF MANAGEMENT}

A

WELL - KNOWN management consultant, Colonel L. Urwick, discusses in a small booklet* the question as to whether management is or is not regarded as a profession, and puts forward the view that the problem is not wholly academic or a matter of words. It can have considerable influence on such questions as whether or not during the next few years Britain will be able to pay its debts or must face a falling standard of life for its people. All that is necessary to establish the claim of management to professional status is to prove that it involves some branch of learning; in other words; that there is a body of knowledge bearing on the activity of management which can be taught and learned. In 1951 there were nearly seven hundred educational institutions in the United States awarding degrees at university standard in management subjects; the number of university students 'majoring' in this field was more than 370,000 , and just over eighty thousand degrees were awarded.

In Great Britain the figures were proportionately much smaller; but a number of universities have degree courses in management. An intermediate examination in management subjects has been established, and it is national policy that technical colleges should provide facilities for those who wish to prepare for it. If there is no body of knowledge bearing on management which can be taught and learned, all these activities are meaningless. On what then, asks Colonel Urwick, is the resistance to this conclusion among certain business men founded ? The suggestion that management is becoming professionalized seems to many 'practical business men' to threaten with the 'theorizing' that they so much dislike the very area which they had previously regarded as the special citadel of practicality. Secondly, many men in responsible positions to-day are wholly innocent of any formal preparation for their tasks. They have learned the technique and customs of their particular trade or industry by 'experience'.

It is always difficult for the individual to resist the conclusion that the process which launched his peculiar abilities upon the community was wisely conceived. The tendency to become laudator temporis acti and exaggerated loyalty to 'the old school' have similar roots in the eternal fidelity of human nature to itself. The very suggestion of new and improved methods of training which will systematize and shorten the acquisition of experience seems to many a direct threat to their personal integrity.

Others again are concerned lest, if young men who have not yet won their spurs are allowed to study the art of management, they will become overimpressed with their own theoretical knowledge. There is some truth in this. Most young men under twenty-five who have had the benefit of a higher

* Is Management a Profession ? By L. Urwick. Pp. 27. (London: Urwick, Orr and Partners, Lta., 1954.) 


\section{January 1, 1955 \\ WELDING IN SHIP CONSTRUCTION}

VOL. 175 education pass through a period when they overestimate the force of logical argument and underestimate the mutability of things. It is a condition which the older men of wisdom learn to recognize and to correct with kindly tolerance.

Another traditional attitude which plays a part in this picture, curiously at variance with our preference for the 'practical', is the British prejudice in favour of amateurishness. In business, being a director is still, in part, a stronghold of the amateur. Many men are made directors of companies who have neither worked their way up through the ranks of management nor have qualified themselves professionally in other ways. They often represent important financial interests, which should be represented, but have no knowledge of the art and science of management or of the technique of the particular industry or trade with which the company is concerned. To suggest to men who have absorbed this national prejudice in favour of amateurishness that business management should be treated as a profession seems deeply shocking.

There are certain historical reasons why the title 'director' in business has become one of the last bastions of this erumbling edifice of social prejudice. It is no accident that the highest class in the British Civil Service, that into which university graduates are recruited direct and from which the majority of the highest posts are filled, is known as the Administrative Class. The second grade, recruited from secondary-school students, is termed the Executive Class. Executive work - that is, managementcommands far less social prestige in Great Britain than in the United States, where the greatest elective office in the world, the presidency, is by definition an executive office.

The proposition that management should be treated as a profession cuts across many of these quasi-understandings and habitual ways of thinking, some of them with their roots deep in British history. It means recognizing the employee, the salaried man with managerial duties, as much less sharply distinguished from the director than has been the case in the past.

Finally, in this order of objections, comes fear. In recent years the leaders of business in Great Britain have had an uneasy time. The Second World War exposed them to an orgy of government regulation from which they have not yet entirely escaped. Men who have been thus harried are bound to be sensitive beyond the normal, to feel that any suggestion that their salaried employees are going to act together-and professional status does connote some form of professional organization which might, however improbably, issue in bargaining conditions-should be resisted at all costs.

The objections to regarding management as a profession are all of them subjective. They are fears, feelings, folk-ways, customary attitudes, prejudices in favour of, or against, this or that; and the best way to deal with a non-logical impulse or habit of thought which cannot be defended by argument-and any argument in favour of social distinctions is deeply out of sympathy with the spirit of the time-is to ignore it, to push it away below the threshold of consciousness. Yet, assuming that the word management is used of the activity normally understood by the word and confined strictly to executive functions, there seems to be no insuperable practical obstacle to the professional organization of those engaged in this occupation.
$\mathrm{D}^{\mathrm{u}}$ URING the Second World War a large number of merchant ships were built in the United States, at a rate of production which could only have been achieved with the extensive use of welding. In the circumstances, it is not sumprising that a proportion of these ships should have suffered structural failure when in service. It is now clear that most of the failures were examples of notch brittle fracture, such as has been experienced from time to time in many types of steel structure, both riveted and welded, on land and at sea, ever since iron and steel have been in common use. At the time, however, it was widely believed that the welded ships wore intrinsically more prone to fracture than their riveted counterparts. With a different pattern of production, the British shipbuilding industry was not at that time faced with a similar problem. In spite of this, the Admiralty Ship Welding Committee was set up in 1943 with terms of reference, "To consider and investigate special problems arising from the employment of welding in ship's structures and to advise on methods for their solution". This Committee has just been disbanded, and its last report has been issued*.

Much of the work of the Committee was devoted to metallurgical studies relating to notch brittle fracture, and it is in this direction that the most radical changes have been proposed. Nevertheless, it was necessary to distinguish the differences in structural behaviour, if any should exist, between riveted and welded ships of otherwise identical design. The series of trials carried out for this purpose deserve wide recognition for their excellence of planning and execution. Four ships were chosen for the major trials. Of these, two were 12,000-ton tankers and two were 10,000-ton dry-cargo ships. The ships of each pair were identical, except for the alternatives of welded and riveted joints. In addition to the more obvious differences of design between the tankers and the dry-cargo ships, the former had a preponderance of shell framing in the longitudinal, and the latter in the transverse direction. Although the primary object of the tests was to compare the stress distributions to which the riveted and welded ships would be subjected at sea, it was decided that this could not be undertaken directly. Alternatively, on one only, the welded dry-cargo ship Ocean Vulcan, an extensive investigation was made, not only of the forces which North Atlantic sea conditions produced, but also of the stresses and deflexions which similar forces produced when applied in still water by means of ballast loadings. The latter were chosen to simulate various vertical and horizontal bending-moment conditions, shear forces and torsion moments. The still-water investigations were also carried out for each of the remaining ships.

*Admiralty Ship Welding Committee. Report No. R.6: Structural Tests in Still Water on Welded Dry Cargo Ship Ocean Vulcan. Pp: $x+50+25$ plates +109 diagrams +8 tables. 30s. net. Meport No. R.7 :
Structural Tests in Still Water on Riveted Dry Cargo Ship Clan Alpine. Pp. x+18+16 plates +116 diagrams +9 tables. 30s. net. Alpine. $P$ p. $\mathrm{x}+18+16$ plates +116 diagrams +9 tables. 308 . net. Report No. R.8: \$.S. Ocean Vulcan Sea Trials--The Forces Acting No. R.9: Ocean Vulcan Sea Trials-Detailed Analysis of Record No. I. E.3 (Loaded Condition). Pp. viii $+17+87$ diagrams. 258. net. Report No. R.10: Ocean Vulcan Sea Trials-Detailed Analysis of Record No. 6. E.7 (Loaded Condition). Pp. viii + 200 (187 pages of diagrams). 42s. net. Report No. R.11 : S.S. Ocean Vulcan Sea Trials. Detailed Analysis of Record No. 6 . W.5 (Ballast Condition). Pp. viii $+12+124$ diagrams. 27s. $6 d$. net. Report No. R.12: Structural Trials on S.S. Ocean Vuican and S.S. Clan Alpine. Discussion of Results. (In the press.) (London: H.M. Stationery Office, 1953 and 1954.) 